\title{
Ameliorative effects of Artemisia argyi Folium extract on 2,4-dinitrochlorobenzene-induced atopic dermatitis-like lesions in BALB/c mice
}

\author{
HYOUNG-MIN HAN $^{1}$, SEUNG-JU KIM ${ }^{1}$, JONG-SIK KIM ${ }^{2}$, BUM HOI KIM ${ }^{3}$, \\ HAI WOONG LEE ${ }^{4}$, YONG TAE LEE ${ }^{1}$ and KYUNG-HWA KANG ${ }^{1}$
}

\author{
${ }^{1}$ Department of Physiology, College of Korean Medicine, Dong-Eui University, Busan 614-851; \\ ${ }^{2}$ Department of Anatomy, College of Medicine, Kosin University, Busan 602-703; Departments of ${ }^{3}$ Anatomy and ${ }^{4}$ Public Health, \\ College of Korean Medicine, Dong-Eui University, Busan 614-851, Republic of Korea
}

Received July 11, 2015; Accepted July 21, 2016

DOI: $10.3892 / \mathrm{mmr} .2016 .5657$

\begin{abstract}
Artemisia argyi Folium has been used to treat skin diseases, including eczema and dermatitis, in South Korean medicine. The present study investigated the curative effects of Artemisia argyi Folium extract (AAFE) on 2,4-dinitrochlorobenzene (DNCB)-induced atopic dermatitis (AD)-like skin lesions in a BALB/c mouse model. Briefly, the dorsal skin of the $\mathrm{BALB} / \mathrm{c}$ mice was sensitized three times with $\mathrm{DNCB}$, whereas the ears were challenged twice. Repeated treatment with DNCB induced AD-like lesions. The effects of AAFE on AD-like lesions were evaluated by clinical observation, histopathological analysis, immunohistochemistry and enzyme-linked immunosorbent assay. In addition, reverse transcription-polymerase chain reaction and western blotting were performed. Treatment with AAFE reduced AD-like lesions, as determined by clinical observation, histopathological analysis, and detection of the serum levels of histamine, immunoglobulin E and cytokines. With regards to its mechanism of action, AAFE inhibited the phosphorylation of Lck/yes-related novel tyrosine kinase (Lyn), spleen tyrosine kinase (Syk), mitogen-activated protein kinases (MAPKs), phosphoinositide 3-kinase (PI3K)/Akt and $\mathrm{I} \kappa \mathrm{B} \alpha$, which have essential roles in the production of various cytokines in lymph nodes. The suppressive activity of AAFE may be due to the inhibition of a series of immunopathological events, including the release of proinflammatory cytokines. The results of the present study strongly suggest that AAFE exerts an anti-AD effect by inhibiting the Lyn, Syk, MAPKs, PI3K/Akt and $\mathrm{I} \kappa \mathrm{B} \alpha$ pathways. Therefore, AAFE may be considered an effective herbal remedy for the treatment of $\mathrm{AD}$.
\end{abstract}

Correspondence to: Dr Kyung-Hwa Kang, Department of Physiology, College of Korean Medicine, Dong-Eui University, 52-57 Yangjeong-ro, Busanjin-gu, Busan 614-851, Republic of Korea E-mail: ghkang@deu.ac.kr

Key words: Artemisia argyi Folium, 2,4-dinitrochlorobenzene, atopic dermatitis

\section{Introduction}

Artemisia argyi Folium has long been used as an herbal treatment or moxibustion in the traditional medicine of East Asian countries. It is used widely to treat various chronic diseases, including osteoarthritis, asthma, gastrointestinal disorders, dysmenorrhea and insomnia (1-5). Several studies have reported that compounds isolated from Artemisia argyi Folium have antitumor, anti-inflammatory and anti-allergic effects (6-14); however, to the best of our knowledge, a study using whole Artemisia argyi Folium extract (AAFE) has not yet been performed.

Atopic dermatitis (AD) is a common relapsing inflammatory skin disease, which is associated with the following symptoms: Erythema, eczema, pruritus, xerosis and lichenification (15). $\mathrm{AD}$ is characterized by several immune disorders, and patients with AD present high levels of histamine and immunoglobulin (Ig)E. The cytokine milieu consists of T helper (Th)2 cytokines, including interleukin (IL)-4, IL-6 and IL-13; Th1 cytokines, including transforming growth factor (TGF)- $\beta$ and interferon (IFN)- $\gamma$; and non-Th proinflammatory cytokines, including IL-1 $\beta$ and tumor necrosis factor (TNF)- $\alpha$ throughout the acute and chronic phases of AD (16-18).

Overproduction of soluble mediators, including histamine, IgE and cytokines, is associated with activation of cell signaling molecules, including Lck/yes-related novel tyrosine kinase (Lyn), spleen tyrosine kinase (Syk), mitogen-activated protein kinases (MAPKs), phosphoinositide 3-kinase (PI3K)/AKT and $\mathrm{I} \kappa \mathrm{B} /$ nuclear factor kappa-light-chain-enhancer of activated $\mathrm{B}$ cells $(\mathrm{NF}-\kappa \mathrm{B})$ in AD pathogenesis (19-22). The present study aimed to investigate whether AAFE is able to alleviate the pathological symptoms of multiplex immune disorders through the regulation of intracellular signaling pathways in an animal model of 2,4-dinitrochlorobenzene (DNCB)-induced AD.

\section{Materials and methods}

Animals. Female BALB/c mice were purchased from Hyochang Science (Daegu, South Korea) and were 8 weeks old at the initiation of the present study. Mice were maintained 
in a temperature-controlled room $\left(23 \pm 1^{\circ} \mathrm{C}\right)$ with relative humidity $(50 \pm 10 \%)$ and underwent a $12 \mathrm{~h}$ light/dark cycle. The mice were housed in polystyrene cages at Dong-Eui University (Busan, South Korea) and were given ad libitum access to standard rodent chow and water. The mice used in the present study were cared for according to the Guide for the Care and Use of Laboratory Animals (23). The experimental protocol was approved by the Institutional Animal Research Committee of Dong-Eui University on Animal Care and Use (Approval number: DEU-R2014-015), and all efforts were made to minimize animal suffering and reduce the number of animals used in the experiments.

Preparation of $A A F E$. AAFE was isolated from Artemisia argyi Folium purchased from Omniherb Co., Ltd. (Daegu, South Korea). A total of $100 \mathrm{~g}$ Artemisia argyi Folium was mixed with $1 \mathrm{~L} 75 \%$ ethanol at $60^{\circ} \mathrm{C}$, and was incubated for $24 \mathrm{~h}$ with agitation $(90 \mathrm{rpm})$. The extract was filtered and evaporated using a rotary evaporator under a reduced pressure. The extract was subsequently lyophilized, and the extract yield was $20.5 \%$. A voucher specimen (DKMP-201203-AAFE) was deposited at Korean Medical Physiology Laboratory, Dong-Eui University. The extracted powder was stored at $-20^{\circ} \mathrm{C}$ until further use.

Induction of $A D$-like skin lesions and administration of $A A F E$. The backs of the BALB/c mice were shaved using an electric clipper and depilatory cream, and were washed with sterilized phosphate-buffered saline (PBS)-gauze 1 day prior to sensitization. During the sensitization process, $100 \mu 12 \%$ DNCB (dissolved in 100\% ethanol; Sigma-Aldrich, St. Louis, MO, USA) or vehicle (100\% ethanol) was applied to the shaved backs of the DNCB-immunized or non-immunized mice on days 0,3 and 6 . On days 13 and 16, $20 \mu 10.2 \%$ DNCB or vehicle was used to challenge the ears of the mice.

The BALB/c mice (age, 8 weeks) were randomized into four groups ( $n=5 /$ group): Non-immunized (normal), DNCB-immunized (control), and DNCB-immunized AAFE (AAFE 0.5 and AAFE 1)-treated groups. Mice in the AAFE 0.5 and AAFE 1 groups were orally administered 0.5 or $1 \mathrm{~g} / \mathrm{kg}$ AAFE dissolved in saline, respectively, once daily for 10 days. Normal and control groups were administered the same volume of saline for 10 days (Fig. 1A). Following completion of the experiments, the mice were anesthetized with diethyl ether $(2 \mathrm{~g} / \mathrm{kg})$ and whole blood samples were collected from the mice by cardiac puncture. The mice were sacrificed by extended diethyl ether $(2 \mathrm{~g} / \mathrm{kg})$ inhalation, and the ear tissues and lymph nodes were removed and stored at $-70^{\circ} \mathrm{C}$ until further analysis.

Histopathology. A total of 16 days after AD induction, the mice were anesthetized with diethyl ether, and the ear tissues were excised. Part of the excised tissue was fixed in $4 \%$ paraformaldehyde (Sigma-Aldrich) for $24 \mathrm{~h}$, embedded in paraffin, and used to prepare $5-\mu \mathrm{m}$ sections. The sections were subsequently deparaffinized in xylene, rehydrated, and stained with hematoxylin and eosin (H\&E). The sections were examined under a light microscope (Olympus Corporation, Tokyo, Japan).

Immunohistochemistry. Immunohistochemistry was performed using the floating method. The deparaffinized sections were then treated with $10 \%$ normal goat serum (ab138478; Abcam, Cambridge, UK) for $1 \mathrm{~h}$ at $4^{\circ} \mathrm{C}$, in order to prevent unspecified immune reactions, followed by incubation with mouse anti-TGF- $\beta 1$ (cat. no. ab9758; 1:100 dilution; rabbit polyclonal; Abcam) overnight at $4{ }^{\circ} \mathrm{C}$. The sections were then incubated for $1 \mathrm{~h}$ at room temperature with a biotinylated anti-mouse IgG antibody (Vectastatin ABC kit; Vector Laboratories, Inc., Burlingame, CA, USA), and were finally incubated with the ABC complex (1:100) for $1 \mathrm{~h}$. Peroxidase was visualized using $0.05 \%$ 3,3'-diaminobenzidine and $0.01 \%$ hydrogen peroxide in Tris-buffered saline (TBS). The specificity of the immunoreaction was tested by incubating sections without primary antibody. The expression was calculated from the percentage of immunopositive cells in $10^{5} \mu \mathrm{m}^{2}$.

Histamine assay. Serum histamine levels were measured according to the $o$-phthaldialdehyde spectrofluorometric method (24). Blood samples from the mice were centrifuged for $10 \mathrm{~min}$ at $4^{\circ} \mathrm{C}$ and $400 \mathrm{x}$ g, and the extracted serum was used to measure histamine levels. Briefly, a mixture of $22.5 \mu 10.1 \mathrm{~N}$ $\mathrm{HCl}$ and $2.5 \mu 170 \% \mathrm{HClO}_{4}$ was added to $25 \mu 1$ serum and centrifuged at $350 \mathrm{xg}$ for $10 \mathrm{~min}$ at $4^{\circ} \mathrm{C}$. The upper phase $(40 \mu \mathrm{l})$ was then transferred to tubes containing $25 \mu 15 \mathrm{~N} \mathrm{NaOH}, 0.06 \mathrm{~g}$ $\mathrm{NaCl}$ and $500 \mu \mathrm{ln}$-butanol, and the sample was centrifuged at $350 \mathrm{x}$ g for $10 \mathrm{~min}$ at $4^{\circ} \mathrm{C}$ to remove contaminated materials from the upper phase. The lower phase $(400 \mu \mathrm{l})$ was transferred to tubes containing $150 \mu 10.1 \mathrm{~N} \mathrm{HCl}$ and $500 \mu \mathrm{l}$ n-heptane, and the sample was centrifuged at $350 \mathrm{xg}$ for $10 \mathrm{~min}$ at $4^{\circ} \mathrm{C}$. The lower phase $(100 \mu \mathrm{l})$ was subsequently transferred to tubes containing $200 \mu 11 \mathrm{~N} \mathrm{NaOH}$ and $5 \mu 11 \% o$-phthaldialdehyde, and incubated for $3 \mathrm{~min}$ at room temperature. The reaction was terminated by the addition of $10 \mu 13 \mathrm{~N} \mathrm{HCl}$, and fluorescence intensity was measured at an excitation wavelength of $360 \mathrm{~nm}$ and an emission wavelength of $450 \mathrm{~nm}$ using the Fluorescence Spectrometer Spectramax M2 (Molecular Devices, LLC, Sunnyvale, CA, USA). The percentage of histamine release was calculated as follows: Histamine release $(\%)=(\mathrm{AAFE}$ or Control / Normal) x 100.

Enzyme-linked immunosorbent assay (ELISA). Total serum IgE and cytokine (IL-1 $\beta$, IL-4, IL-6 and IFN- $\gamma$ ) levels were quantified using the mouse IL-1 $\beta$, (cat. no. 559603) IL-4 (cat.no.555232),IL-6(cat.no.555240) andIFN- $\gamma$ (cat.no.551866) OptEIA $^{\mathrm{TM}}$ sandwich ELISA Quantitation kits (BD Biosciences, San Diego, CA, USA) according to the manufacturer's protocol. The total levels in the blood serum were calculated using a linear regression equation obtained from standard absorbance values.

Reverse transcription-polymerase chain reaction ( $R T-P C R)$. Total RNA was isolated from the skin-draining lymph nodes using TRIzol ${ }^{\circledR}$ reagent (Invitrogen; Thermo Fisher Scientific, Inc., Waltham, MA, USA) according to the manufacturer's protocol. The primers used to amplify IL-1 $\beta$, IL-4, IL-6, IL-13, TNF- $\alpha$, IFN- $\gamma$, granulocyte-macrophage colony-stimulating factor (GM-CSF) and glyceraldehyde 3-phosphate dehydrogenase (GAPDH) are shown in Table I and were purchased from Bioneer, Inc. (Seoul, Korea). Total RNA $(1 \mu \mathrm{g})$ and total reagents $(20 \mu 1)$ were used with One-step RT-PCR PreMix (iNtRON Biotechnology, Inc., Seongnam, Korea) for RT-PCR. The 
Table I. Oligonucleotide reverse transcription-polymerase chain reaction primers used in the present study.

\begin{tabular}{|c|c|c|c|}
\hline Gene & Sequences $\left(5^{\prime} \rightarrow 3^{\prime}\right)$ & Size (bp) & Accession no. \\
\hline IL-1 $\beta$ & $\begin{array}{l}\text { Sense AAG CTC TCC ACC TCA ATG GAC A } \\
\text { Anti-sense GTC TGC TCA TTC ACG AAA ABB GAG }\end{array}$ & 453 & NM_008361.3 \\
\hline IL-4 & $\begin{array}{l}\text { Sense ACC TTG CTG TCA CCC TCT TC } \\
\text { Anti-sense TTG TGA GCG TGG ACT CAT TC }\end{array}$ & 351 & NM_021283 \\
\hline IL-6 & $\begin{array}{l}\text { Sense TCC AGT TGC CTT CTT GGG AC } \\
\text { Anti-sense GTG TAA TTA AGC CTC CGA CTT G }\end{array}$ & 100 & NM_031168.1 \\
\hline IL-13 & $\begin{array}{l}\text { Sense GCT CTC GCT TGC CTT GGT GGT C } \\
\text { Anti-sense CAT CCG AGG CCT TTT GGT TAC AG }\end{array}$ & 218 & NM_008355.3 \\
\hline TNF- $\alpha$ & $\begin{array}{l}\text { Sense GCG ACG TGG AAC TGG CAG AAG } \\
\text { Anti-sense TCC ATG CCG TTG GTT AGG AGG }\end{array}$ & 340 & NM_013693.3 \\
\hline IFN- $\gamma$ & $\begin{array}{l}\text { Sense TCA AGT GGC ATA GAT GTC GAA GAA } \\
\text { Anti-sense TGG CTC TGC AGG ATT TTC ATG }\end{array}$ & 92 & NM_008337.3 \\
\hline GM-CSF & $\begin{array}{l}\text { Sense GCA TGT AGA TGC CAT CAA AGA AGC } \\
\text { Anti-sense CAT TTC TGG ACC GGC TTC CAG C }\end{array}$ & 342 & X03019.1 \\
\hline GAPDH & $\begin{array}{l}\text { Sense CCA CAG TCC ATG CCA TCA C } \\
\text { Anti-sense TCC ACC ACC CTG TTG CTG TA }\end{array}$ & 568 & NM_008084.3 \\
\hline
\end{tabular}

IL, interleukin; TNF- $\alpha$, tumor necrosis factor- $\alpha$; IFN- $\gamma$, interferon- $\gamma$; GM-CSF, granulocyte-macrophage colony-stimulating factor; GAPDH, glyceraldehyde 3-phosphate dehydrogenase; bp, base pairs.

reverse transcription reaction was performed at $45^{\circ} \mathrm{C}$ for $30 \mathrm{~min}$ and $94^{\circ} \mathrm{C}$ for $2 \mathrm{~min}$, then the PCR reaction was performed at $94^{\circ} \mathrm{C}$ for $30 \mathrm{sec}$ (denaturation), $55-56^{\circ} \mathrm{C}$ for $30 \mathrm{sec}$ (annealing), and $72^{\circ} \mathrm{C}$ (extention) for $1 \mathrm{~min}$, and repeated for 30 cycles followed by incubation at $72^{\circ} \mathrm{C}$ for $7 \mathrm{~min}$. The PCR reaction was performed using a GeneAmp PCR system 9700 (Applied Biosystems; Thermo Fisher Scientific, Inc.). The PCR products were subsequently separated by $2 \%$ (w/v) agarose gel electrophoresis and were stained with ethidium bromide. GAPDH was used as a housekeeping gene for each experimental condition.

Western blotting. The skin-draining lymph nodes were homogenized with ice-cold lysis buffer, which consisted of $20 \mathrm{mmol} / 1$ Tris- $\mathrm{HCl}$ (pH 8.0), $150 \mathrm{mmol} / \mathrm{l} \mathrm{NaCl}, 2 \mathrm{mmol} / \mathrm{l}$ ethylenediaminetetraacetic acid, $1 \mathrm{mmol} / 1 \mathrm{NaF}, 1 \%$ Igepal CA-630, $1 \mathrm{mmol} / 1$ phenylmethylsulfonyl fluoride, $1 \mathrm{mmol} / 1 \mathrm{Na}_{3} \mathrm{VO}_{4}$, and protease inhibitor cocktail. Following a $10 \mathrm{~min}$ incubation on ice, the homogenized suspension was centrifuged at 2,000 x g for $15 \mathrm{~min}$ at $4^{\circ} \mathrm{C}$, and the supernatant was used to determine protein concentrations. The protein concentration in the tissue lysates was determined using a protein assay kit (Bio-Rad Laboratories, Inc., Hercules, CA, USA). Total proteins (25 $\mu \mathrm{g}$ from each sample) were then separated by $10 \%$ sodium dodecyl sulfate-polyacrylamide gel electrophoresis and were transferred to nitrocellulose transfer membranes (Whatman; GE Healthcare Europe GmbH, Freiburg, Germany). The membranes were blocked with $5 \%$ skim milk in TBS-Tween (TBST) buffer [10 mmol/1 Tris- $\mathrm{HCl}(\mathrm{pH} 7.5), 150 \mathrm{mmol} / 1$ $\mathrm{NaCl}$ and $0.05 \%$ Tween 20) for $1 \mathrm{~h}$, and were then incubated with phospho-specific or total antibodies to Lyn; Syk; MAPK family members: Extracellular signal-regulated kinase (ERK), c-jun N-terminal kinase (JNK) and p38; PI3K; Akt; IкB $\alpha$; and $\beta$-actin. The membranes were incubated with the primary antibodies (diluted in 5\% skim milk in TBST) overnight at $4^{\circ} \mathrm{C}$ and were then washed. The membranes were subsequently incubated for $1 \mathrm{~h}$ at room temperature with horseradish peroxidase-conjugated anti-mouse IgG or anti-rabbit IgG antibodies (diluted in 5\% skim milk in TBST). Immunoreactive bands were developed using enhanced chemiluminescence (ECL) regents (Pierce ECL Western Blotting Substrate; Thermo Fisher Scientific, Inc.) according to the manufacturer's protocol. The primary and secondary antibodies used in the present study and the dilutions used are listed in Table II.

Statistical analysis. Data from the control or drug-treated groups are presented as the mean \pm standard deviation of three independent experiments and each experiment includes triplicate sets in vitro and of five animals per group in vivo. Data were analyzed using one-way analysis of variance followed by Dunnett's post-hoc test in the GraphPad Prism 5 package (GraphPad Software Inc., San Diego, CA, USA). $\mathrm{P}<0.05$ were considered to indicate a statistically significant difference.

\section{Results}

Progression of AD-like skin lesions in BALB/c mice. The representative clinical features of the treatment groups are presented in Fig. 1B. Repeated application of DNCB induced skin dryness, followed by erythema, edema and hyperemia in the ear of the control group. However, the AAFE 0.5 and AAFE 1 groups exhibited inhibition of these symptoms of AD (Fig. 1B).

Histopathological and immunohistochemical features. Histopathological features of the ear skin lesions are presented in Fig. 2A. In the normal group, inflammatory cell infiltration was not observed following H\&E staining. However, in the 
Table II. Primary and secondary antibodies used in the present study.

\begin{tabular}{|c|c|c|c|}
\hline Antibody & Cat. no. & Source & Dilution \\
\hline \multicolumn{4}{|l|}{ Primary antibodies } \\
\hline TGF- $\beta 1$ & ab9758 & Abcam, Cambridge, UK & $1: 100$ \\
\hline Lyn/p-Lyn & $\# 2732 \mathrm{~S} / 2731 \mathrm{~S}$ & Cell Signaling Technologies, Inc., Beverly, MA, USA & $1: 1,000$ \\
\hline Syk/p-Syk & sc-1077/sc293118 & Santa Cruz Biotechnology, Inc., Dallas, TX, USA & $1: 1,000$ \\
\hline ERK/p-ERK & \#9102/\#9101S & Cell Signaling Technologies, Inc. & $1: 1,000$ \\
\hline $\mathrm{JNK} / \mathrm{p}-\mathrm{JNK}$ & \#9151S/\#9251S & Cell Signaling Technologies, Inc., & $1: 1,000$ \\
\hline p38/p-p38 & \#9212/\#9211S & Cell Signaling Technologies, Inc., & $1: 1,000$ \\
\hline $\mathrm{PI} 3 \mathrm{~K} / \mathrm{p}-\mathrm{PI} 3 \mathrm{~K}$ & \#4292S/\#4228S & Cell Signaling Technologies, Inc., & $1: 1,000$ \\
\hline $\mathrm{Akt} / \mathrm{p}-\mathrm{Akt}$ & \#9272/\#9271S & Cell Signaling Technologies, Inc., & $1: 1,000$ \\
\hline $\mathrm{I} \kappa \mathrm{B} \alpha / \mathrm{p}-\mathrm{I} \kappa \mathrm{B} \alpha$ & \#9242/\#9246S & Cell Signaling Technologies, Inc., & $1: 1,000$ \\
\hline$\beta$-actin & sc-47778 & Santa Cruz Biotechnology, Inc. & $1: 1,000$ \\
\hline \multicolumn{4}{|l|}{ Secondary antibodies } \\
\hline Goat anti-rabbit IgG, pAb & ADI-SAB-300-J & Enzo Life Sciences, Inc., Farmingdale, NY, USA & $1: 5,000$ \\
\hline Goat anti-mouse $\operatorname{IgG}, \mathrm{pAb}$ & ADI-SAB-100-J & Enzo Life Sciences, Inc. & $1: 2,500$ \\
\hline
\end{tabular}

TGF- $\beta 1$, transforming growth factor- $\beta 1$; Lyn, Lck/yes-related novel tyrosine kinase; Syk, spleen tyrosine kinase; ERK, extracellular signal-regulated kinase; JNK, c-jun N-terminal kinase; PI3K, phosphatidylinositol 3-kinase; p-, phosphorylated; IgG, immunoglobulin G; pAb, polyclonal antibody.

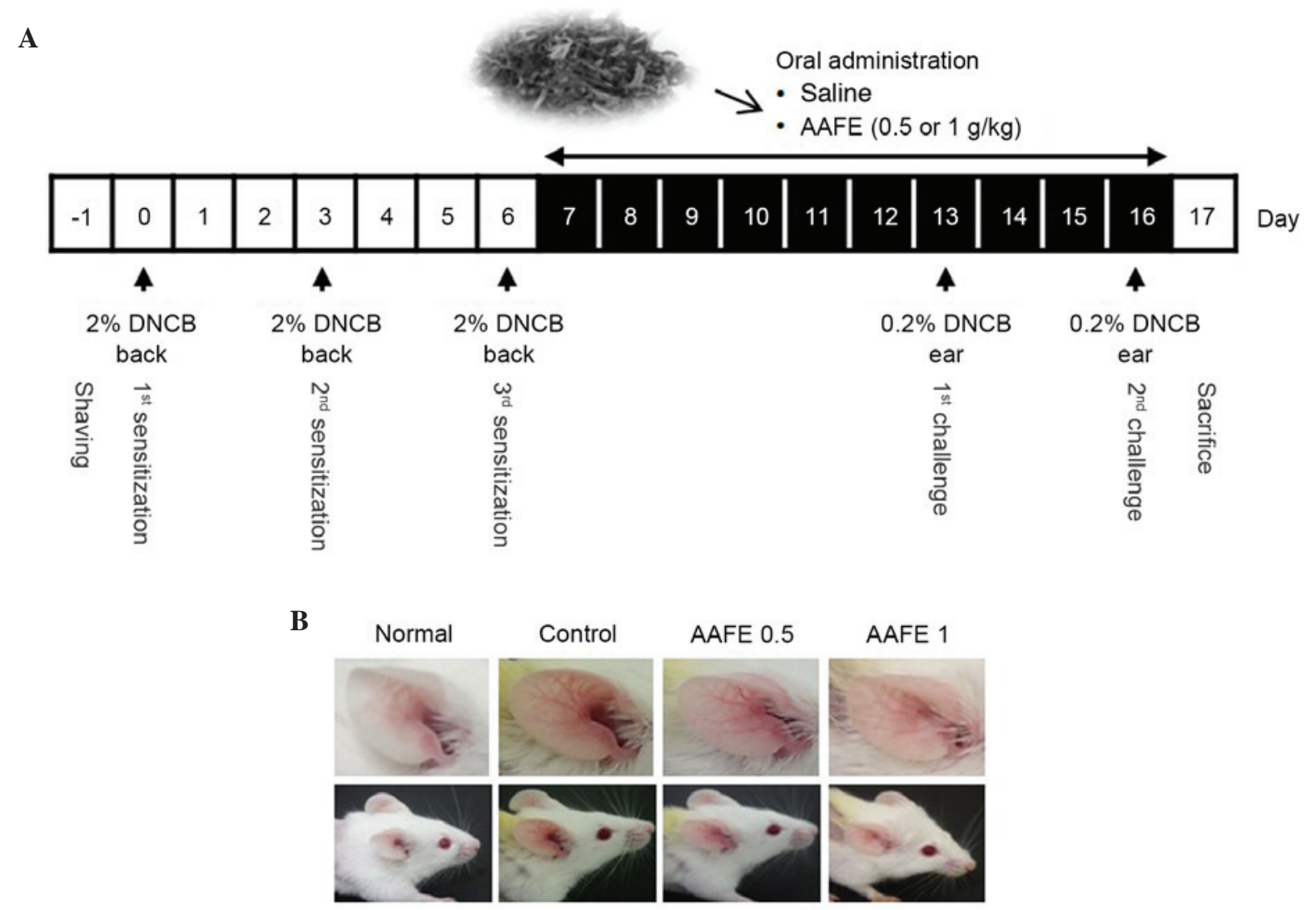

Figure 1. Experimental protocols and inhibition of DNCB-induced AD progression by topical application of AAFE in BALB/c mice. (A) Experimental schedule for the induction of AD-like skin lesions and oral administration of AAFE. (B) Representative images of the ear skin from each group are shown. DNCB, 2,4-dinitrochlorobenzene; AD, atopic dermatitis; AAFE, Artemisia argyi Folium extract.

control group inflammatory cell infiltration of the dermis was observed. Inhibition of these histopathological alterations was observed in the AAFE 0.5 and AAFE 1 groups compared with the control group (Fig. 2Aa-d). Immunohistochemistry was performed to evaluate DNCB-induced TGF- $\beta 1$ expression in the AD-like lesions. TGF- $\beta 1$ was not detected in the epidermis 
A

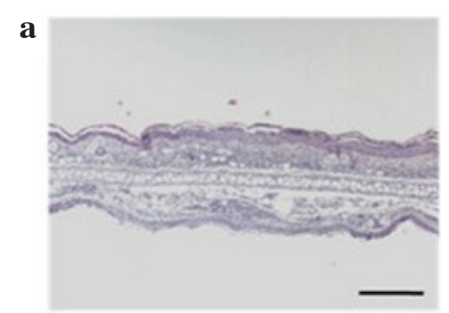

C

e

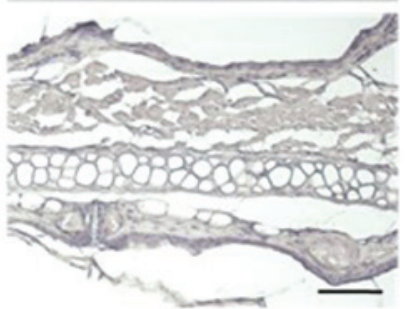

g

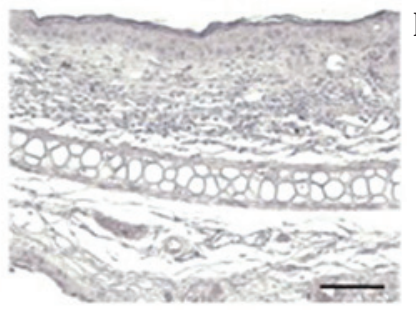

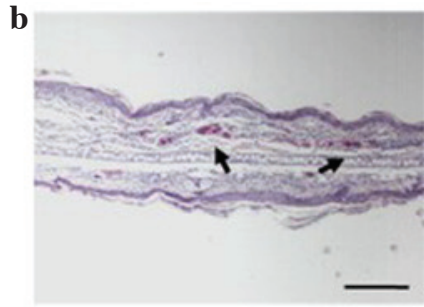

b

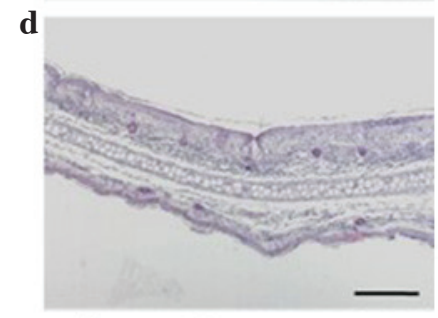

f

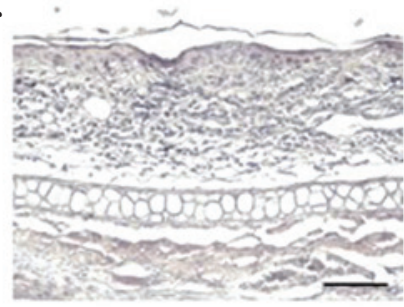

h

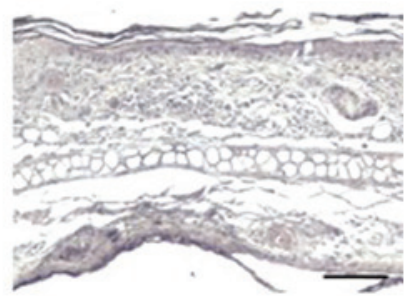

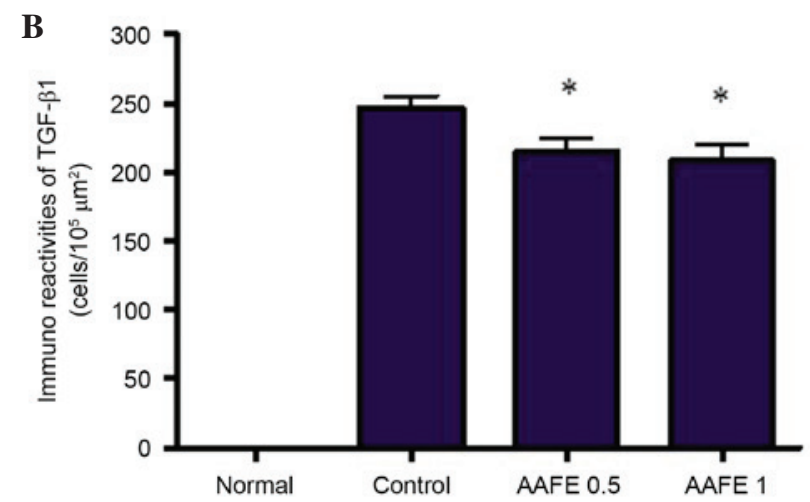

Figure 2. Hematoxylin and eosin staining and TGF- $\beta 1$ immunohistochemical staining of ear skin tissue in BALB/c mice. (A) (a) Inflammatory responses were not observed in the normal group. (b) The control group exhibited marked increases in inflammatory response, and the (c) AAFE $0.5 \mathrm{~g} / \mathrm{kg}$ and (d) AAFE $1 \mathrm{~g} / \mathrm{kg}$ groups exhibited relative decreases compared with the control group. Markedly increased protein levels of TGF- $\beta 1$ were detected in the (f) control group compared with the (e) normal group. Protein expression levels of TGF- $\beta 1$ were decreased in the (g) AAFE $0.5 \mathrm{~g} / \mathrm{kg}$ and (h) AAFE $1 \mathrm{~g} / \mathrm{kg}$ groups compared with the control group. Scale Bar: a-d=50 $\mu \mathrm{m}$; e- $\mathrm{h}=100 \mu \mathrm{m}$. (B) Immunohistochemical staining of ear skin tissue for TGF- $\beta 1$. The number of TGF- $\beta 1-p o s i t i v e$ cells was significantly decreased in the AAFE $0.5 \mathrm{~g} / \mathrm{kg}$ and AAFE $1 \mathrm{~g} / \mathrm{kg}$ groups compared with the control group. Data are presented as the mean \pm standard deviation from five animals. Data were analyzed using one-way analysis of variance followed by Dunnett's post-hoc multiple comparison test. $\mathrm{P}<0.05$ vs. the control group. AAFE, Artemisia argyi Folium extract; TGF- $\beta 1$, transforming growth factor- $\beta 1$.

and dermis of the normal group; however, marked TGF- $\beta 1$ expression was detected in the epidermis and dermis of the control group. Conversely, the number of TGF- $\beta 1$-expressing cells was markedly lower in the AAFE 0.5 and AAFE 1 groups compared with that of the control group (Fig. 2Ae-h and $2 \mathrm{~B}$ ).
Effects of AAFE on serum levels of histamine and IgE. To assess the inhibitory effects of AAFE on histamine and $\operatorname{IgE}$ production by DNCB-induced AD-like lesions, histamine and IgE levels were measured in the serum. The control group displayed significant increases in histamine and $\operatorname{IgE}$ levels compared with the normal group, whereas the AAFE 0.5 and 
Histamine

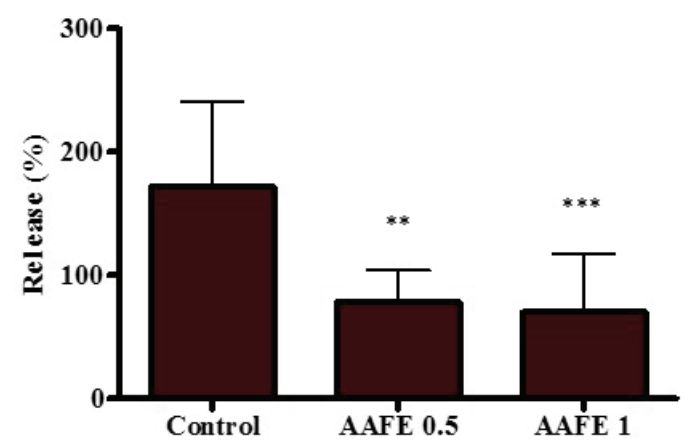

IgE

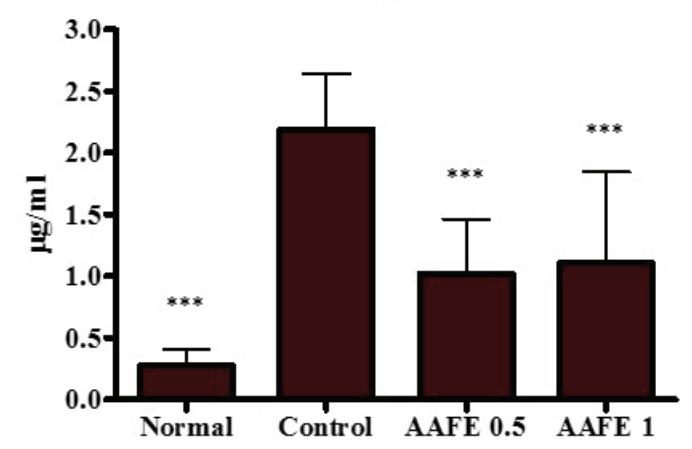

Figure 3. Effects of AAFE on serum levels of histamine and IgE. Data are presented as the mean \pm standard deviation from five animals. Histamine levels are presented as a percentage relative to the normal levels of histamine release. Data were analyzed using one-way analysis of variance followed by Dunnett's post-hoc multiple comparison test. ${ }^{* *} \mathrm{P}<0.01,{ }^{* * *} \mathrm{P}<0.001$ vs. the control group. AAFE, Artemisia argyi Folium extract; IgE, immunoglobulin E.

AAFE 1 groups exhibited suppressed histamine and IgE levels compared with the control group (Fig. 3).

Effects of AAFE on serum cytokine production and $m R N A$ expression of cytokines in skin-draining lymph nodes. To assess the suppressive effects of AAFE on the production and gene expression of cytokines in DNCB-induced AD-like lesions, the serum levels of IL- $1 \beta$, IL- 4 , IL- 6 and IFN- $\gamma$ cytokines, and the mRNA expression levels of diverse cytokines were determined in the skin-draining lymph nodes. The control group exhibited significant increases in serum levels of IL-1 $\beta$, IL-4, IL- 6 and IFN- $\gamma$ compared with the normal group, whereas the AAFE 0.5 and AAFE 1 groups exhibited suppressed serum levels of IL-1 $\beta$, IL- 4 , IL-6 and IFN- $\gamma$ compared with the control group (Fig. 4A). Furthermore, the skin-draining lymph nodes of the control group exhibited higher expression levels of IL-1 $\beta$, IL-4, IL-6 and IFN- $\gamma$ compared with in the normal group. In the AAFE 0.5 and AAFE 1 groups the mRNA expression levels of IL-4 and IL-6, which are produced by Th2 cells, and IFN- $\gamma$, which is produced by Th1 cells, were suppressed in a dose-dependent manner. In addition, the AAFE 0.5 and AAFE 1 groups exhibited reduced mRNA expression levels of IL-1 $\beta$, TNF- $\alpha$ and GM-CSF (Fig. 4B).

Effects of AAFE on activation of Lyn, Syk, MAPKs, PI3K/Akt and $I \kappa B \alpha$. Lyn, Syk, MAPKs, PI3K/Akt and I $\kappa$ B $\alpha / \mathrm{NF}-\kappa \mathrm{B}$ signaling pathways have previously been implicated in the pathogenesis of allergic inflammatory skin diseases, and proinflammatory cytokines are known to induce activation of these signaling pathways $(25,26)$. Therefore, the present study investigated whether AAFE regulates Lyn, Syk, MAPKs, PI3K/Akt and I $\mathrm{B} \alpha$ signaling associated with AD-like lesions. As shown in Fig. 5, in the skin-draining lymph nodes of the control group the phosphorylation of Lyn, Syk, MAPKs (ERK, JNK and p38), PI3K/Akt and I $\mathrm{B} \alpha$ were overexpressed compared with the normal group; however, in the AAFE 0.5 and AAFE 1 groups the phosphorylation of Lyn, Syk, MAPKs, (ERK, JNK and p38), PI3K/Akt and I $\mathrm{B} \alpha \alpha$ were suppressed in a dose-dependent manner (Fig. 5).

\section{Discussion}

$\mathrm{AD}$ is an inflammatory, relapsing and itchy skin disorder, which is divided into two phases. Acute AD is characterized by erythema, eczema, excoriation, exudation and pruritus, and represents a Th2-biased immune response. Chronic AD is characterized by dry and thickened skin, lichenification and fibrotic papules, and represents a Th1/Th2/non Th-complexed immune response.

The present study determined the effects of AAFE on DNCB-induced AD-like lesions. Macroscopic observations indicated that AAFE prevented the progression of AD-like pathogenesis through a reduction of clinical symptoms, including eczema and erythema (Fig. 1B).

TGF- $\beta 1$ is a multifunctional cytokine that is implicated in skin dendritic cell homeostasis, fibroblast growth and tissue remodeling. TGF- $\beta 1$ promotes severe skin inflammation, the formation of lichenification and fibrotic papules in AD lesions, and also has an important role in structural changes, such as fibrosis, in chronic lung diseases (27). In the present study, histopathological analysis indicated that AAFE attenuated inflammatory symptoms and TGF- $\beta 1$ immunoreactivities in ear skin tissue (Fig. 2).

IgE-mediated hypersensitive immune responses to generally harmless environmental antigens contribute to the pathogenesis of AD. IgE binds to allergens and induces the aggregation of FceRI on the surface of mast cells/basophils, triggering an allergic cascade through the release of inflammatory mediators, including histamine, prostaglandins, chemokines and cytokines $(28,29)$. The results of the present study suggested that AAFE exerted an inhibitory effect on histamine release and IgE production in the serum (Fig. 3).

The cytokine milieu of patients with AD is known to consist of Th2 cytokines, Th1 cytokines and non-Th proinflammatory cytokines throughout the acute and chronic phases of AD (16-18). The Th2 cytokines, which include IL-4, IL-6 and IL-13, are systemically upregulated in AD, and the typical Th1 cytokine, IFN- $\gamma$, is upregulated in chronic AD-skin lesions (30). Non-Th proinflammatory cytokines, including IL-1 $\beta$ and TNF- $\alpha$, are produced from resident cells such as keratinocytes, mast cells and dendritic cells, thus implying their roles in the initiation and maintenance of atopic 

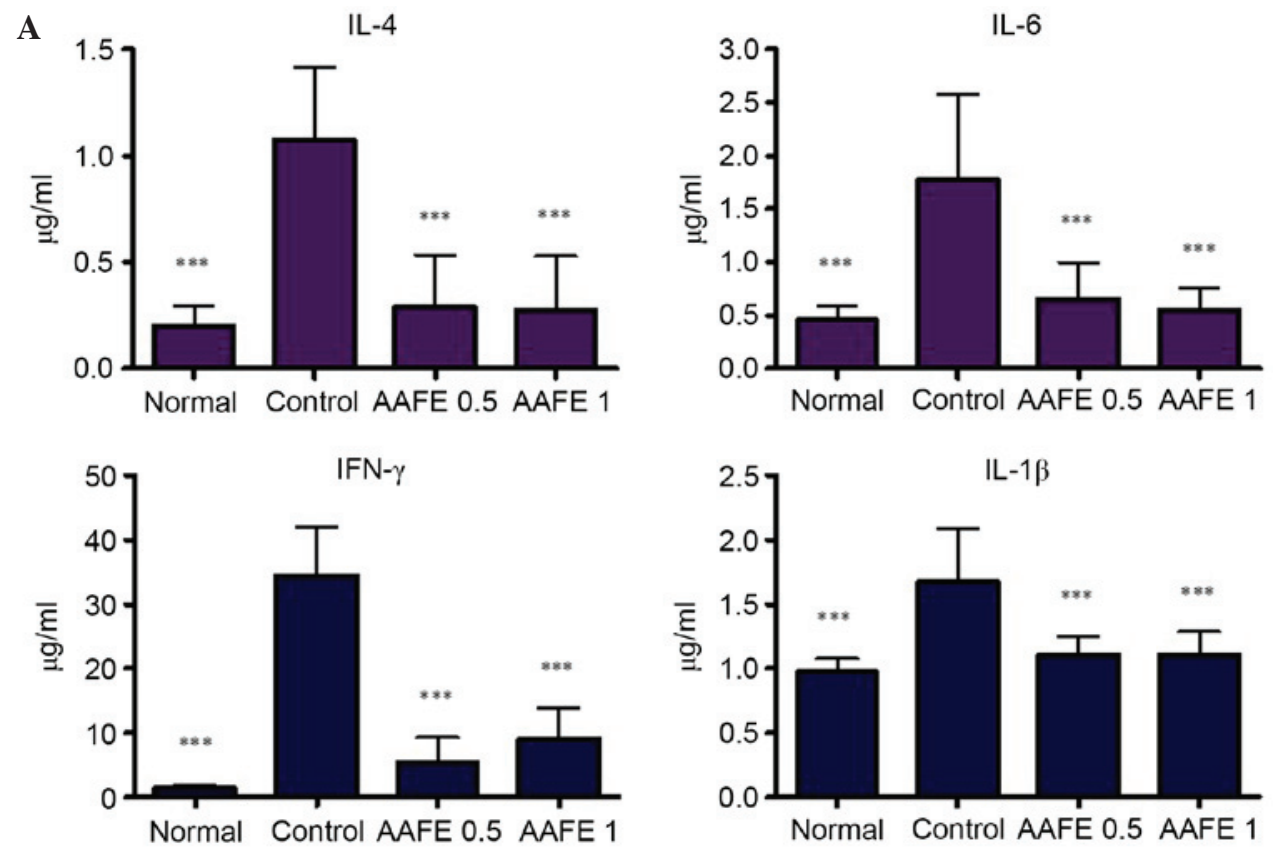

B
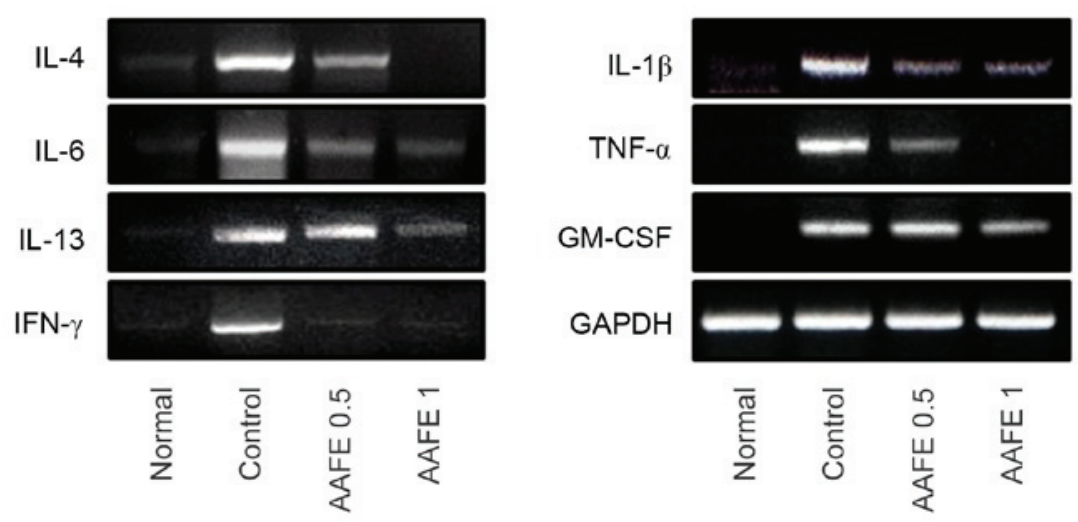

Figure 4. Effects of AAFE on serum levels of IL-4, IL-6, IFN- $\gamma$ and IL-1 $\beta$, and mRNA expression levels of IL-4, IL-6, IL-13, IFN- $\gamma$, IL-1 $\beta$, TNF- $\alpha$ and GM-CSF in skin-derived lymph nodes from a mouse model of AD-like lesions. (A) Serum IL-4, IL-6, IFN- $\gamma$ and IL-1 $\beta$ levels. Data presented as the mean \pm standard deviation from five animals. Data were analyzed using one-way analysis of variance followed by Dunnett's post-hoc multiple comparison test. ${ }^{* * * *} \mathrm{P}<0.001$ vs. the control group. (B) Representative IL-4, IL-6, IL-13, IFN- $\gamma$, IL-1 $\beta$, TNF- $\alpha$ and GM-CSF mRNA expression levels. AAFE, Artemisia argyi Folium extract; IL, interleukin; IFN- $\gamma$, interferon- $\gamma$; TNF- $\alpha$, tumor necrosis factor- $\alpha$; GM-CSF, granulocyte-macrophage colony-stimulating factor; GAPDH, glyceraldehyde 3-phosphate dehydrogenase.
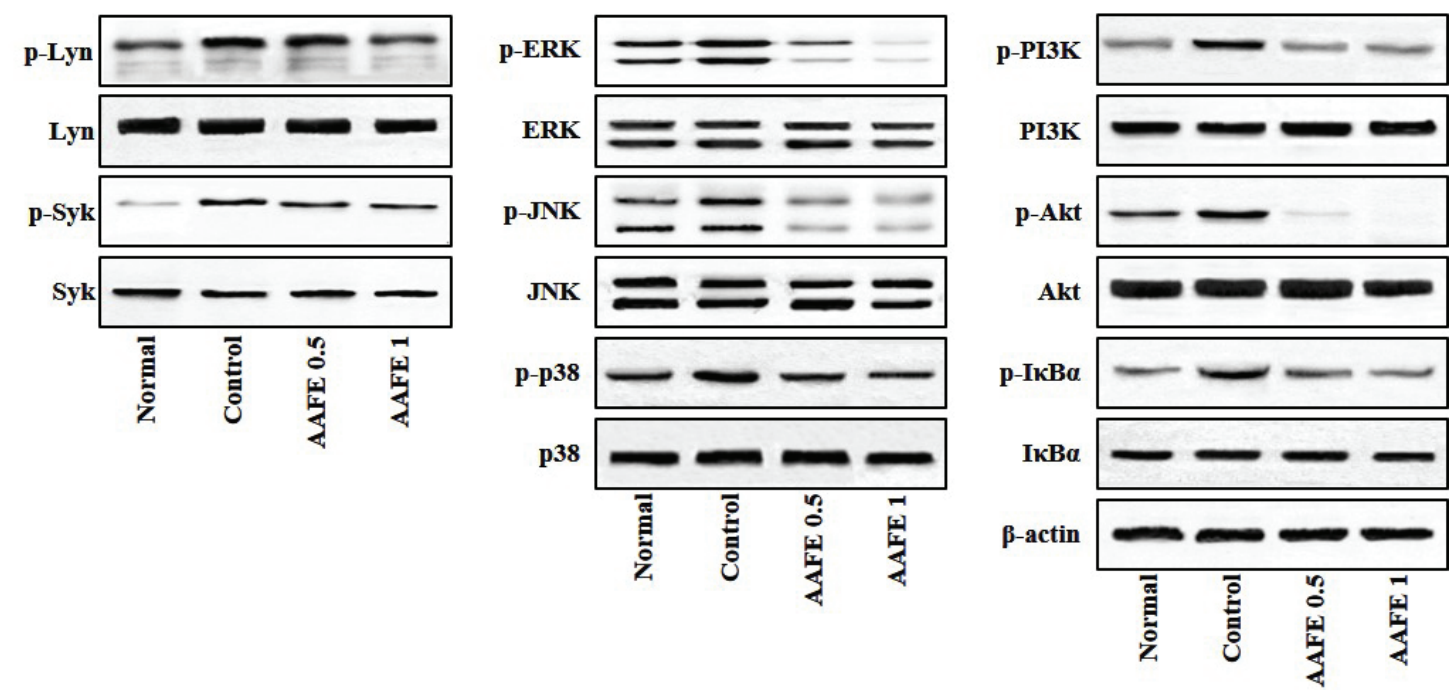

Figure 5. Effects of AAFE on the activation of Lyn, Syk, MAPKs, PI3K/Akt and IkB $\alpha$ in skin-derived lymph nodes from a mouse model of AD-like lesions. Representative Lyn, Syk, MAPKs, PI3K/Akt and IкB $\alpha$ expression levels are presented. Total proteins were analyzed by western blotting using phospho-specific or total antibodies against Lyn, Syk, ERK, JNK, p38, PI3K, Akt, IKB $\alpha$ and $\beta$-actin. p-, phosphorylated; AAFE, Artemisia argyi Folium extract; Lyn, Lck/yes-related novel tyrosine kinase; Syk, spleen tyrosine kinase; ERK, extracellular signal-regulated kinase; JNK, c-jun N-terminal kinase; PI3K, phosphatidylinositol 3-kinase. 
inflammation $(30,31)$. In the present study, treatment with AAFE attenuated serum levels of IL-4, IL-6, IFN- $\gamma$ and IL-1 $\beta$ (Fig. 4A), and the mRNA expression levels of IL-4, IL-6, IL-13, IL-1 $\beta$, TNF- $\alpha$ and GM-CSF in skin-derived lymph nodes (Fig. 4B). These results suggested that oral administration of AAFE may attenuate the excessive cytokine milieu and inflammation in a model of AD-like skin lesions.

The Src-family kinase, Lyn, and the protein tyrosine kinase, Syk, are key regulators in the allergic proximal signaling pathway; these tyrosine kinases lead to the activation and tyrosine phosphorylation of MAPKs, PI3K/Akt and I $\mathrm{B} \alpha$ downstream of Syk $(25,26)$. MAPKs (ERK1/2, p38 and JNK) are involved in the immune response and transduce extracellular signals, including inflammatory cytokines, growth factors and stress stimuli, into intracellular responses such as inflammation, differentiation and apoptosis (32). The PI3K/Akt pathway regulates the mast cell response, which is related to allergic diseases (33). Activation of $N F-\kappa B$ signaling by proinflammatory cytokines mediates the degradation of I $\mathrm{B} \alpha$ and the nuclear translocation of $\mathrm{NF}-\kappa \mathrm{B}$, which consequently induces inflammation and tissue damage (22). In the present study, AAFE inhibited DNCB-induced phosphorylation of Lyn/Syk, MAPKs (ERK, JNK and p38), PI3K/Akt and IкB $\alpha$ (Fig. 5).

In conclusion, the findings of the present study demonstrated that AAFE exerted ameliorative effects on DNCB-induced AD-like lesions, by exerting anti-allergenic skin inflammatory effects related to the recovery of skin barrier dysfunction. These effects may be associated with suppression of cytokine abundance via the regulation of crucial factors, including Lyn, Syk, MAPKs, PI3K/Akt, and I $\mathrm{B} \alpha$, during the process of AD pathogenesis.

The present study aimed to determine whether AAFE exerts therapeutic effects in AD. The anti-AD effects of AAFE were identified, and were shown to be related to suppression of inflammatory actions and skin barrier damage in a mouse model of AD-like skin lesions. Therefore, the effects of AAFE may help improve treatment for various allergic diseases and skin diseases.

\section{Acknowledgements}

The present study was supported by a grant from the Dong-Eui University Foundation (grant no. 2013AA108).

\section{References}

1. Ren X, Yao C, Wu F, Li Z, Xing J and Zhang H: Effectiveness of moxibustion treatment in quality of life in patients with knee osteoarthritis: A randomized, double-blinded, placebo-controlled trial. Evid Based Complement Alternat Med 2015: 569523, 2015.

2. Chen R, Chen M, Xiong J, Chi Z, Zhang B, Tian N, Xu Z, Zhang T, Li W, Zhang W, et al: Curative effect of heat-sensitive moxibustion on chronic persistent asthma: A multicenter randomized controlled trial. J Tradit Chin Med 33: 584-591, 2013.

3. Park JW, Lee BH and Lee H: Moxibustion in the management of irritable bowel syndrome: Systematic review and meta-analysis. BMC Complement Altern Med 13: 247, 2013.

4. Yang J, Yu S, Lao L, Yang M, Chen J, Luo X, Wang Y, Chen X, Li J, Zhu L, et al: Use of moxibustion to treat primary dysmenorrhea at two interventional times: Study protocol for a randomized controlled trial. Trials 16: 35, 2015.
5. Guo J, Wang LP, Liu CZ, Zhang J, Wang GL, Yi JH and Cheng JL: Efficacy of acupuncture for primary insomnia: A randomized controlled clinical trial. Evid Based Complement Alternat Med 2013: 163850, 2013.

6. Jeong MA, Lee KW, Yoon DY and Lee HJ: Jaceosidin, a pharmacologically active flavone derived from Artemisia argyi, inhibits phorbol-ester-induced upregulation of COX-2 and MMP-9 by blocking phosphorylation of ERK-1 and -2 in cultured human mammary epithelial cells. Ann N Y Acad Sci 1095: 458-466, 2007.

7. Lee SH, Bae EA, Park EK, Shin YW, Baek NI, Han EJ, Chung HG and Kim DH: Inhibitory effect of eupatilin and jaceosidin isolated from Artemisia princeps in IgE-induced hypersensitivity. Int Immunopharmacol 7: 1678-1684, 2007.

8. Kim MJ, Han JM, Jin YY, Baek NI, Bang MH, Chung HG, Choi MS, Lee KT, Sok DE and Jeong TS: In vitro antioxidant and anti-inflammatory activities of Jaceosidin from Artemisia princeps Pampanini cv. Sajabal. Arch Pharm Res 31: 429-437, 2008

9. Min SW, Kim NJ, Baek NI and Kim DH: Inhibitory effect of eupatilin and jaceosidin isolated from Artemisia princeps on carrageenan-induced inflammation in mice. J Ethnopharmacol 125: 497-500, 2009.

10. Yin Y, Sun Y, Gu L, Zheng W, Gong F, Wu X, Shen Y and Xu Q: Jaceosidin inhibits contact hypersensitivity in mice via down-regulating IFN- $\gamma / \mathrm{STAT} 1 / \mathrm{T}$-bet signaling in $\mathrm{T}$ cells. Eur J Pharmacol 651: 205-211, 2011.

11. Bao X, Yuan H, Wang C, Liu J and Lan M: Antitumor and immunomodulatory activities of a polysaccharide from Artemisia argyi. Carbohydr Polym 98: 1236-1243. 2013.

12. Wang S, Li J, Sun J, Zeng KW, Cui JR, Jiang Y and Tu PF: NO inhibitory guaianolide-derived terpenoids from Artemisia argyi. Fitoterapia 85: 169-175, 2013.

13. Nam Y, Choi M, Hwang H, Lee MG, Kwon BM, Lee WH and Suk K: Natural flavone jaceosidin is a neuroinflammation inhibitor. Phytother Res 27: 404-411, 2013.

14. Zeng KW, Wang S, Dong X, Jiang Y and Tu PF: Sesquiterpene dimer(DSF-52) from Artemisia argyi inhibits microglia-mediated neuroinflammation via suppression of NF- $\kappa \mathrm{B}, \mathrm{JNK} / \mathrm{p} 38$ MAPKs and Jak2/Stat3 signaling pathways. Phytomedicine 21: 298-306, 2014.

15. Spergel JM and Paller AS: Atopic dermatitis and the atopic march. J Allergy Clin Immunol 112 (Suppl 6): S118-S127, 2003.

16. Akdis CA, Akdis M, Trautmann A and Blaser K: Immune regulation in atopic dermatitis. Curr Opin Immunol 12: 641-646, 2000.

17. Peng W and Novak N: Pathogenesis of atopic dermatitis. Clin Exp Allergy 45: 566-574, 2015.

18. Chen L, Martinez O, Overbergh L, Mathieu C, Prabhakar BS and Chan LS: Early up-regulation of Th2 cytokines and late surge of Th1 cytokines in an atopic dermatitis model. Clin Exp Immunol 138: 375-387, 2004.

19. Dickinson RJ and Keyse SM: Diverse physiological functions for dual-specificity MAP kinase phosphatases. J Cell Sci 119: 4607-4615, 2006.

20. Sabio G and Davis RJ: TNF and MAP kinase signalling pathways. Semin Immunol 26: 237-245, 2014.

21. Fruman DA and Bismuth G: Fine tuning the immune response with PI3K. Immunol Rev 228: 253-272, 2009.

22. Wullaert A, Bonnet MC and Pasparakis M: NF- $\mathrm{B}$ in the regulation of epithelial homeostasis and inflammation. Cell Res 21: 146-158, 2011.

23. National Research Council (US) Committee for the Update of the Guide for the Care and Use of Laboratory Animals: Guide for the Care and Use of Laboratory Animals. 8th edition. National Academies Press (US), Washington (DC), USA, 2011.

24. Shore PA, Burkhalter A and Cohn VH Jr: A method for the fluorometric assay of histamine in tissues. J Pharmacol Exp Ther 127: 182-186, 1959.

25. Sanderson MP, Wex E, Kono T, Uto K and Schnapp A: Syk and Lyn mediate distinct Syk phosphorylation events in FceRI-signal transduction: Implications for regulation of IgE-mediated degranulation. Mol Immunol 48: 171-178, 2010.

26. Siraganian RP, de Castro RO, Barbu EA and Zhang J: Mast cell signaling: The role of protein tyrosine kinase Syk, its activation and screening methods for new pathway participants. FEBS Lett 584: 4933-4940, 2010. 
27. Lee KS, Park SJ, Kim SR, Min KH, Lee KY, Choe YH, Hong SH, Lee YR, Kim JS, Hong SJ, et al: Inhibition of VEGF blocks TGF-beta1 production through a PI3K/Akt signalling pathway. Eur Respir J 31: 523-531, 2008

28. Gilfillan AM and Beaven MA: Regulation of mast cell responses in health and disease. Crit Rev Immunol 31: 475-529, 2011.

29. Kalesnikoff J and Galli SJ: New developments in mast cell biology. Nat Immunol 9: 1215-1223, 2008.

30. Leung DY, Boguniewicz M, Howell MD, Nomura I and Hamid QA: New insights into atopic dermatitis. J Clin Invest 113: 651-657, 2004.
31. Schuepbach-Mallepell S, Philippe V, Brüggen MC, Watanabe H, Roques S, Baldeschi C and Gaide O: Antagonistic effect of the inflammasome on thymic stromal lymphopoietin expression in the skin. J Allergy Clin Immunol 132: 1348-1357, 2013.

32. Peti W and Page R: Molecular basis of MAP kinase regulation. Protein Sci 22: 1698-1710, 2013.

33. Kim MS, Rådinger M and Gilfillan AM: The multiple roles of phosphoinositide 3-kinase in mast cell biology. Trends Immunol 29: 493-501, 2008. 